\title{
Mapping, cluster detection and evaluation of risk factors of ovine toxoplasmosis in Southern Italy
}

\author{
Roberto Condoleo, ${ }^{1}$ Vincenzo Musella, ${ }^{2}$ Maria Paola Maurelli, ${ }^{3}$ Antonio Bosco, ${ }^{3}$ \\ Giuseppe Cringoli, ${ }^{3}$ Laura Rinaldi ${ }^{3}$ \\ ${ }^{1}$ IZSLT, Institute for Experimental Veterinary Medicine of Latium and Tuscany, Rome; \\ ${ }^{2}$ Department of Health Sciences, Magna Græcia University, Catanzaro; ${ }^{3}$ Department of \\ Veterinary Medicine and Animal Productions, University of Naples Federico II, Regional \\ Centre for Monitoring of Infectious Diseases, Campania Region, Naples, Italy
}

\begin{abstract}
Toxoplasmosis, an important cause of reproductive failure in sheep, is responsible for significant economic losses to the ovine industry worldwide. Moreover, ovine meat contaminated by the parasite Toxoplasma gondii is considered as a common source of infection for humans. The aim of this study was to develop point and risk profiling maps of T. gondii seroprevalence in sheep bred in Campania Region (Southern Italy) and analyse risk factors associated at the flock-level. We used serological data from a previous survey of 117 sheep flocks, while environmental and farm management information were obtained from an analysis based on geographical information systems and a questionnaire purveyance, respectively. An univariate Poisson regression model revealed that the type of farm production (milk and meat $v s$ only meat) was the only independent variable associated with T. gondii positivity $(\mathrm{P}<0.02)$; the higher within-flock seroprevalence in milking herds suggests that milking practices might influence the spread of the infection on the farm. Neither environmental nor other management variables were significant. Since a majority of flocks were seasonally or permanently on pasture, the animals have a high
\end{abstract}

Correspondence: Laura Rinaldi, Department of Veterinary Medicine and Animal Productions, University of Naples Federico II, via Della Veterinaria 1, 80137 Naples, Italy.

Tel: +39.081 .2536283 - Fax: +39.081 .2536280 .

E-mail: Irinaldi@unina.it

Key words: Toxoplasma gondii; Sheep; Epidemiology; Geographical information systems; Italy.

Received for publication: 30 November 2015.

Revision received: 13 May 2016.

Accepted for publication: 16 May 2016.

CC Copyright R. Condoleo et al., 2016

Licensee PAGEPress, Italy

Geospatial Health 2016; 11:432

doi:10.4081/gh.2016.432

This article is distributed under the terms of the Creative Commons Attribution Noncommercial License (CC BY-NC 4.0) which permits any noncommercial use, distribution, and reproduction in any medium, provided the original author(s) and source are credited. exposure to infectious T. gondii oocysts, so the high within-flock seroprevalence might derive from this management factor. However, further studies are needed to better assess the actual epidemiological situation of toxoplasmosis in sheep and to clarify the factors that influence its presence and distribution.

\section{Introduction}

The cosmopolitan protozoan Toxoplasma gondii, able to infect humans and all warm-blooded animals, has a complex life-cycle that involves both intermediate (mammals and birds) and definitive hosts (felids). Hosts are infected through the ingestion of either meat that contains bradyzoites or of oocysts present in the soil or water (Dubey, 2009). Infection by T. gondii in sheep is recognised as a major cause of infectious reproductive failure in several countries of the world by causing foetal resorption, abortion at any stage of pregnancy, foetal mummification, stillbirth or weak offspring (Guo et al., 2015). Toxoplasmosis also causes heavy economic losses to the sheep industry worldwide (Tenter et al., 2000; Innes et al., 2009). Furthermore, infected sheep meat is a relevant source of $T$. gondii infection for humans (Dubey, 2009; Guo et al., 2015). A risk assessment study estimated that consumption of undercooked ovine meat is responsible for 14.0\% of meat-related T. gondii infections in the Dutch population (Opsteegh et al., 2011). Due to the high likelihood of infection of small ruminants, mostly by the horizontal route (ingestion of oocysts), sheep could serve as an indicator of the T. gondii environmental contamination in a given area. Dubey (2009) reviewed data on T. gondii seroprevalence in sheep since 1988 in different parts of the world, showing high values (up to 95.7\%), but the different studies were not comparable, because different serological tests had been used and different cut-off values applied. Similarly, the review by Rinaldi and Scala (2008) on toxoplasmosis in livestock in Italy shows high seroprevalence of $T$. gondii in sheep (up to 88.6\%). However, this study did not find a uniform distribution in the country as a whole; which could depend on the adoption of different laboratory techniques or different sampling methods of farms and animals as well as specific, environmental or management factors. Only few studies have focused on particular risk factors associated with $T$. gondii seropositivity in sheep (reviewed in Dubey, 2009) and even if spatial investigations have been conducted to study the parasitic infection in domestic animals (Casartelli-Alves et al., 2015; Djoki et al., 2014; Afonso et al., 2013) and wild animal species (Miller et al., 2004; Johnson et al., 2009; Ahlers et 
al., 2015; Chadwick et al., 2013; VanWormer et al, 2013, 2014), geospatial tools have rarely been used for the detection of clustering and/or identification of environmental factors which could affect the T. gondii seroprevalence in small ruminants. The objectives of this study were to: i) develop $T$. gondii distribution maps and risk profiles based on seropositivity in sheep bred in an Italian region (Campania) where sheep farming is important; and ii) further explore the environmental and management risk factors for T. gondii infection in sheep. For both aims, geographical information system (GIS) technology was used as the analytical tool (Rinaldi et al., 2015).

\section{Materials and Methods}

\section{Data source}

The Italian Animal Register (2016) reports that 194,310 animals are currently bred in 6332 ovine farms (averagely 30 sheep per flock) in Campania Region (Southern Italy). In this region, sheep are usually raised by an extensive rearing system (animals are not confined but pastured most of the time). Serological data on T. gondii exposure were derived from a regional cross-sectional survey of 117 sheep farms in the Campania Region (Fusco et al., 2007). The study had been designed to test 10 adult sheep ( $>18$ months old) randomly chosen from each farm; 333 of 1170 animals (28.5\%) were positive by the immunofluorescent antibody technique (IFAT) at the titre $\geq 1: 200$, while $77.8 \%$ of the flocks had at least one seropositive sheep (for details, see Fusco et al., 2007). It should be noted that serum samples were uniformly collected at ovine farms using an identified grid-based approach within a GIS as reported in Fusco et al. (2007) in order to uniformly sample the farms throughout the entire region: a grid representing quadrants of $10 \times 10 \mathrm{~km}$ was overlaid on the regional map within the GIS. As a result, the territory of the Campania Region was divided into equal quadrants, the centroid of each quadrant was identified and the farm closest to this centroid was selected among all the farms present in the GIS database. The number of animals per farm varied between 50 and 1350 with an average size of 237 heads per flock. However, no risk factor analysis was performed in the mentioned prevalence study by Fusco et al. (2007).

\section{Geographical information system}

A GIS was used to integrate the data layers on environmental features including administrative boundaries (at the provincial and municipal levels), land cover, elevation, slope direction (aspect) and degree of steepness. Furthermore, the farms chosen for sampling were geo-referenced by inserting their longitudes and latitudes into the GIS as shown in Figure 1. The buffer generation analysis function of GIS

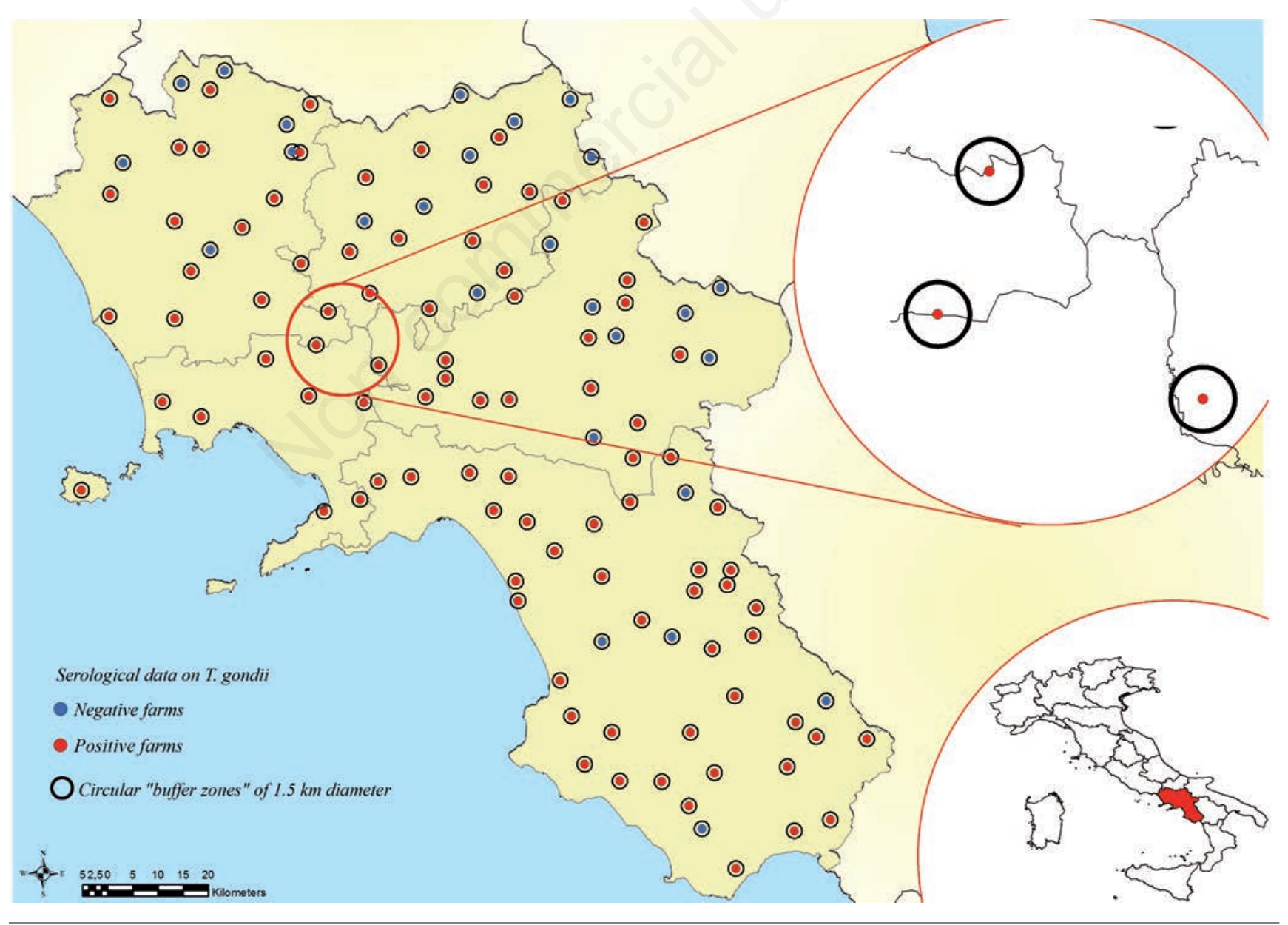

Figure 1. Farms inserted in the geographical information system (geo-referenced), their serological status and generation of circular buffer zones of $1.5-\mathrm{km}$ diameter around each geo-referenced point. 
was used to generate circular buffer zones of $1.5 \mathrm{~km}$ diameter around each geo-referenced point (Figure 1).

\section{Corine Land Cover}

Data on the land cover of the study area were obtained by the Corine Land Cover (CLC) map (version 8/2005; European Environment Agency, Copenhagen K, Denmark), which has a spatial resolution of $100 \mathrm{~m}$. CLC categorises land cover (with some information on land use) hierarchically into three levels and 44 classes. Level 1 includes 5 classes, which correspond to the main categories of land cover/land use (artificial areas, agricultural areas, forests and semi-natural areas, wetlands and water surfaces); level 2 (15 classes) covers physical and physiognomic entities in more detail (e.g., urban zones, type of forests, types of water bodies, etc.); while level 3 is composed of 44 classes based on even more detailed information. CLC was elaborated based on the visual interpretation of satellite-generated images [e.g., SPOT (Spot LLC, Covington, LA, USA), LANDSAT ${ }^{\mathrm{TM}}$ (United States Geological Survey, Reston, VA, USA) and and mobile satellite services, the latter referring to networks of communications satellites intended for use with mobile and portable wireless telephones]. Ancillary data (i.e., aerial photographs, topographic or vegetation maps, statistics and local knowledge) were used to refine interpretation and the assignment of the territory to the CLC class. For each buffer zone identified with the GIS the predominant CLC class was considered.

\section{Elevation, slope and aspect}

Data on elevation, slope steepness and aspect of the study area were obtained from a digital elevation model (DEM) having $40 \mathrm{~m}$ spatial resolution. Aspect was divided into the following eight classes: North $\left(337.5-360^{\circ}\right.$ and $\left.0-22.5^{\circ}\right)$, North-East $\left(22.5-67.5^{\circ}\right)$, East $\left(67.5-112.5^{\circ}\right)$, South-East $\left(112.5-157.5^{\circ}\right)$, South $\left(157.5-202.5^{\circ}\right)$, South-West $(202.5$ $\left.247.5^{\circ}\right)$, West $\left(247.5-292.5^{\circ}\right)$ and North-West $\left(292.5-337.5^{\circ}\right)$. The slope steepness was divided into the following four classes: flat $\left(0^{\circ}\right)$, low (1$\left.15^{\circ}\right)$, medium $\left(16-30^{\circ}\right)$ and high $\left(31-54^{\circ}\right)$.

\section{Mapping and clustering}

In order to display the spatial distribution of $T$. gondii detected at the sheep farms (here used as epidemiological units), farm distribution maps were drawn within the GIS. The clustering of test-positive farms was investigated based on location determined by exact coordinates and using two software applications: i) the spatial scan statistic (SatScan) as described by Kulldorff (1997) choosing the analysis approach Purely Spatial Probability Model, Discrete Poisson Scan for Areas with High or Low Rates; and ii) the ArcGis 9.3 (ESRI, Redlands, CA, USA) tool Average Nearest Neighbor Procedure. The latter approach measures the distance between each feature centroid and its nearest neighbour centroid location, then averages all the nearest neighbour distances. If the average distance is less than the average for a hypothetical random distribution, the distribution of the features being analysed should be considered as clustered. If the average distance is greater than a hypothetical random distribution, the features should instead be considered as dispersed.

\section{Questionnaire management data}

Different management variables (type of production, number of animals, presence of other domestic animals at sheep farms, frequency of domestic slaughtering, frequency of grazing, transhumance, elevation of grazing area, size of grazing area, water sources in the main grazing area) related to farm and pasture typology were included in the analysis. This information was obtained by distributing questionnaires to all participating farm owners.

\section{Statistical analyses}

The results of the IFAT serological tests at the farm level (including the number of positive animals per farm) and independent variables associated with farms (environmental data as well as farm management data obtained from the questionnaires) were recorded and double-checked in an Excel spreadsheet (Microsoft, Redmond, WA, USA). A univariate Poisson regression model was used to assess the association between the within-flock prevalence and each risk factor using

Table 1. Mean seroprevalence of Toxoplasma gondii in sheep farms ( $\mathbf{n}=93)$ and environmental factors for the univariate Poisson regression model.

\begin{tabular}{|c|c|c|c|c|}
\hline Environmental factor & Specifications & Farms (n) & Mean prevalence (\%) & $\mathbf{P}$ \\
\hline Land cover class & $\begin{array}{c}\text { Artificial surfaces } \\
\text { Agricultural areas } \\
\text { Forest and semi-natural areas }\end{array}$ & $\begin{array}{c}4 \\
60 \\
29\end{array}$ & $\begin{array}{l}30.0 \\
38.0 \\
31.0\end{array}$ & 0.22 \\
\hline Aspect & $\begin{array}{l}1 \\
2 \\
3 \\
4 \\
5 \\
6 \\
7 \\
8\end{array}$ & $\begin{array}{c}19 \\
4 \\
11 \\
11 \\
13 \\
19 \\
9 \\
7\end{array}$ & $\begin{array}{l}40.5 \\
25.0 \\
31.8 \\
48.1 \\
31.5 \\
31.6 \\
31.1 \\
37.1\end{array}$ & 0.19 \\
\hline DEM & $\begin{array}{c}0-500 \mathrm{amsl} \\
501-1000 \mathrm{~m} \text { amsl } \\
\text { Above } 1000 \mathrm{~m} \text { amsl }\end{array}$ & $\begin{array}{c}57 \\
29 \\
7\end{array}$ & $\begin{array}{l}35.6 \\
36.6 \\
30.0\end{array}$ & 0.70 \\
\hline Slope & $\begin{array}{c}\text { Flat } \\
\text { Low } \\
\text { Medium } \\
\text { High }\end{array}$ & $\begin{array}{c}14 \\
68 \\
8 \\
3\end{array}$ & $\begin{array}{r}43.5 \\
34.4 \\
37.5 \\
16.7\end{array}$ & 0.12 \\
\hline
\end{tabular}

DEM, digital elevation model; amsl, above mean sea level. 
the number of positive animals in a farm as the dependent variable (Cenci-Goga et al., 2013) and a Log-link function. Farms with presence of dubious reactive animals (serum titres 1:100) or not associated questionnaire data were excluded from statistical analysis of management data (no.=24 farms). The statistical analysis was performed using SPSS (IBM, Armonk, NY, USA).

\section{Results}

The results of the regression model of environmental and farm data are shown in Table 1. Among our farm management factors, the type of production (milk or meat) was the unique variable statistically associated with the within-flock prevalence; the occurrence of $T$. gondii was significantly higher in farms with mixed production than farms where animals are bred only for the meat production (Table 2).

Regarding the environmental factors, more than half of the farms were located at an altitude of 0-500 $\mathrm{m}$ above the mean sea level (amsl). The average altitude for all the farms was 476.2 amsl (min. 12-max. 1594). Besides, almost all of them were distributed within areas characterised by low slope steepness $\left(0-15^{\circ}\right)$ with a median for all the farms of $5.5^{\circ}$ (min 0 -max 33.4 ). The farms had a uniform southern exposure $\left(189.4^{\circ}\right)$. Elevation of the farm was thus not seen to be related to the seroprevalence but we found that the seropositive rate of flocks, which grazed in mountain pastures was lower than flocks which had their

Table 2. Mean seroprevalence of Toxoplasma gondii in sheep farms (n=93) and management factors for the univariate Poisson regression model.

\begin{tabular}{|c|c|c|c|c|}
\hline Management factor & Specifications & Farms (n) & Mean prevalence $(\%)$ & $\mathbf{P}$ \\
\hline Type of production & $\begin{array}{c}\text { Meat } \\
\text { Milk and meat }\end{array}$ & $\begin{array}{l}10 \\
83\end{array}$ & $\begin{array}{l}22.0 \\
37.1\end{array}$ & $0.02^{*}$ \\
\hline Number of animals & $\begin{array}{l}<101 \text { animals } \\
\text { 101-300 animals } \\
>300 \text { animals }\end{array}$ & $\begin{array}{l}31 \\
33 \\
29\end{array}$ & $\begin{array}{l}36.8 \\
33.0 \\
36.9\end{array}$ & 0.64 \\
\hline Presence of sheep from other farms & $\begin{array}{l}\text { No } \\
\text { Yes }\end{array}$ & $\begin{array}{l}81 \\
12\end{array}$ & $\begin{array}{l}36.7 \\
27.5\end{array}$ & 0.11 \\
\hline Presence of animals of different species & $\begin{array}{l}\text { No } \\
\text { Yes }\end{array}$ & $\begin{array}{l}24 \\
69\end{array}$ & $\begin{array}{l}37.9 \\
34.6\end{array}$ & 0.46 \\
\hline Presence of animals from other farms & $\begin{array}{l}\text { No } \\
\text { Yes }\end{array}$ & $\begin{array}{l}71 \\
22\end{array}$ & $\begin{array}{l}36.5 \\
32.3\end{array}$ & 0.36 \\
\hline Presence of bovines & $\begin{array}{l}\text { No } \\
\text { Yes }\end{array}$ & $\begin{array}{l}62 \\
31\end{array}$ & $\begin{array}{l}36.8 \\
32.9\end{array}$ & 0.35 \\
\hline Presence of goats & $\begin{array}{l}\text { No } \\
\text { Yes }\end{array}$ & $\begin{array}{l}43 \\
50\end{array}$ & $\begin{array}{l}37.7 \\
33.6\end{array}$ & 0.29 \\
\hline Presence of cats & $\begin{array}{l}\text { No } \\
\text { Yes }\end{array}$ & $\begin{array}{l}68 \\
25 \\
\end{array}$ & $\begin{array}{l}35.3 \\
36.0 \\
\end{array}$ & 0.87 \\
\hline Presence of pigs & $\begin{array}{c}\text { No } \\
\text { Yes }\end{array}$ & $\begin{array}{l}82 \\
11\end{array}$ & $\begin{array}{l}34.8 \\
40.9\end{array}$ & 0.31 \\
\hline Presence of wild animals & $\begin{array}{l}\text { No } \\
\text { Yes }\end{array}$ & $\begin{array}{l}28 \\
65\end{array}$ & $\begin{array}{l}40.0 \\
33.5\end{array}$ & 0.13 \\
\hline Presence of dogs & $\begin{array}{l}\text { No } \\
\text { Yes }\end{array}$ & $\begin{array}{l}11 \\
82\end{array}$ & $\begin{array}{l}38.2 \\
35.1\end{array}$ & 0.61 \\
\hline Frequency of domestic slaughtering & $\begin{array}{l}\text { Sporadically } \\
\text { Never } \\
\text { Often }\end{array}$ & $\begin{array}{l}58 \\
14 \\
8\end{array}$ & $\begin{array}{l}33.3 \\
45.7 \\
27.5 \\
\end{array}$ & 0.42 \\
\hline Frequency of grazing & $\begin{array}{l}\text { Permanent } \\
\text { Seasonal } \\
\text { Sporadic }\end{array}$ & $\begin{array}{c}68 \\
19 \\
3\end{array}$ & $\begin{array}{l}33.7 \\
40.5 \\
40.0\end{array}$ & 0.34 \\
\hline Transhumance & $\begin{array}{c}\text { No } \\
\text { Yes }\end{array}$ & $\begin{array}{l}74 \\
19 \\
\end{array}$ & $\begin{array}{l}36.8 \\
30.5\end{array}$ & 0.19 \\
\hline Elevation of the grazing area & $\begin{array}{c}\text { Plain }(<300 \mathrm{~m} \text { asl }) \\
\text { Hill }(300-700 \mathrm{~m} \text { asl }) \\
\text { Mountain }(>700 \mathrm{~m} \text { asl })\end{array}$ & $\begin{array}{l}22 \\
36 \\
22\end{array}$ & $\begin{array}{l}33.6 \\
39.4 \\
28.2\end{array}$ & 0.08 \\
\hline Size of the grazing area & $\begin{array}{c}\text { Small ( } \leq 10 \mathrm{he}) \\
\text { Medium }(11-99 \mathrm{he}) \\
\text { Large }(\geq 100 \mathrm{he})\end{array}$ & $\begin{array}{l}23 \\
27 \\
34\end{array}$ & $\begin{array}{l}36.5 \\
37.4 \\
33.2 \\
\end{array}$ & 0.65 \\
\hline Water sources in the main grazing area & $\begin{array}{l}\text { Absence } \\
\text { Presence }\end{array}$ & $\begin{array}{l}31 \\
62\end{array}$ & $\begin{array}{l}36.1 \\
35.2\end{array}$ & 0.81 \\
\hline
\end{tabular}

asl, above sea level. *Statistically highly significant. 
main pasture area at lower elevation (however only at $\mathrm{P}=0.08$ ). The spatial statistical analysis showed that there no clusters correlated to the environmental factors, neither according to SatScan (relative risk: 0, $\log$ likelihood ratio: 2.363769 and $\mathrm{P}=0.98$ ), nor the Average Nearest Neighbor tool ( $\mathrm{Z}$ score: 0.83 and $\mathrm{P}=0.71$ ). The results of our statistical analysis did not show association between presence of cats in farm or grazing area and the serological prevalence, neither was any evidence found supporting that the contact with other animal species can be a risk factor for ovine toxoplasmosis (Table 2). We did not find any statistical relationship with the seroprevalence of the parasite and presence of a water source in the main grazing area (Table 2). Figure 2 reports comparison between serological results and the obtained predominant CLC classes, and DEM data (elevation, aspect and slope steepness).

\section{Discussion}

GIS has been used in other studies to study risk factors of toxoplasmosis in different domestic species (Afonso et al., 2013; Djokic et al.,
2014; Casartelli-Alves et al., 2015). Spatial investigations demonstrated significant variation in seroprevalence of infection in goats between different regions in Serbia (Djokic et al., 2014). In some studies, GIS were used to study the association between prevalence of toxoplasmosis in animals and geographical/climate factors. Afonso et al. (2013) reported that places with a high farm density and cool and moist winter may pose a higher risk of toxoplasmosis in cats. Distance from water sources $(>500 \mathrm{~m})$ and proximity to dense vegetation $(\leq 500 \mathrm{~m})$ were found to influence the probability of infection in chickens (CasartelliAlves et al., 2015). Similar studies have also been conducted on wild animals: sea otters, feral domestic cats and wild felids, foxes and coyotes (Miller et al., 2004; Johnson et al., 2009; Ahlers et al., 2015; Chadwick et al., 2013; VanWormer et al., 2013, 2014). However, this is the first spatial analysis of mapping, cluster detection and risk factors of toxoplasmosis in ovine species based on GIS. Although no significant association with elevation of the farm was detected, we have to consider that sheep-rearing system is not intensive in Campania Region, so sheep are rarely confined to stables. On the contrary, they have access to permanent or frequent grazing (Table 2). As a consequence, taking into account this scenario, the position of the farm may be considered as a minor factor compared to the location of the grazing area.

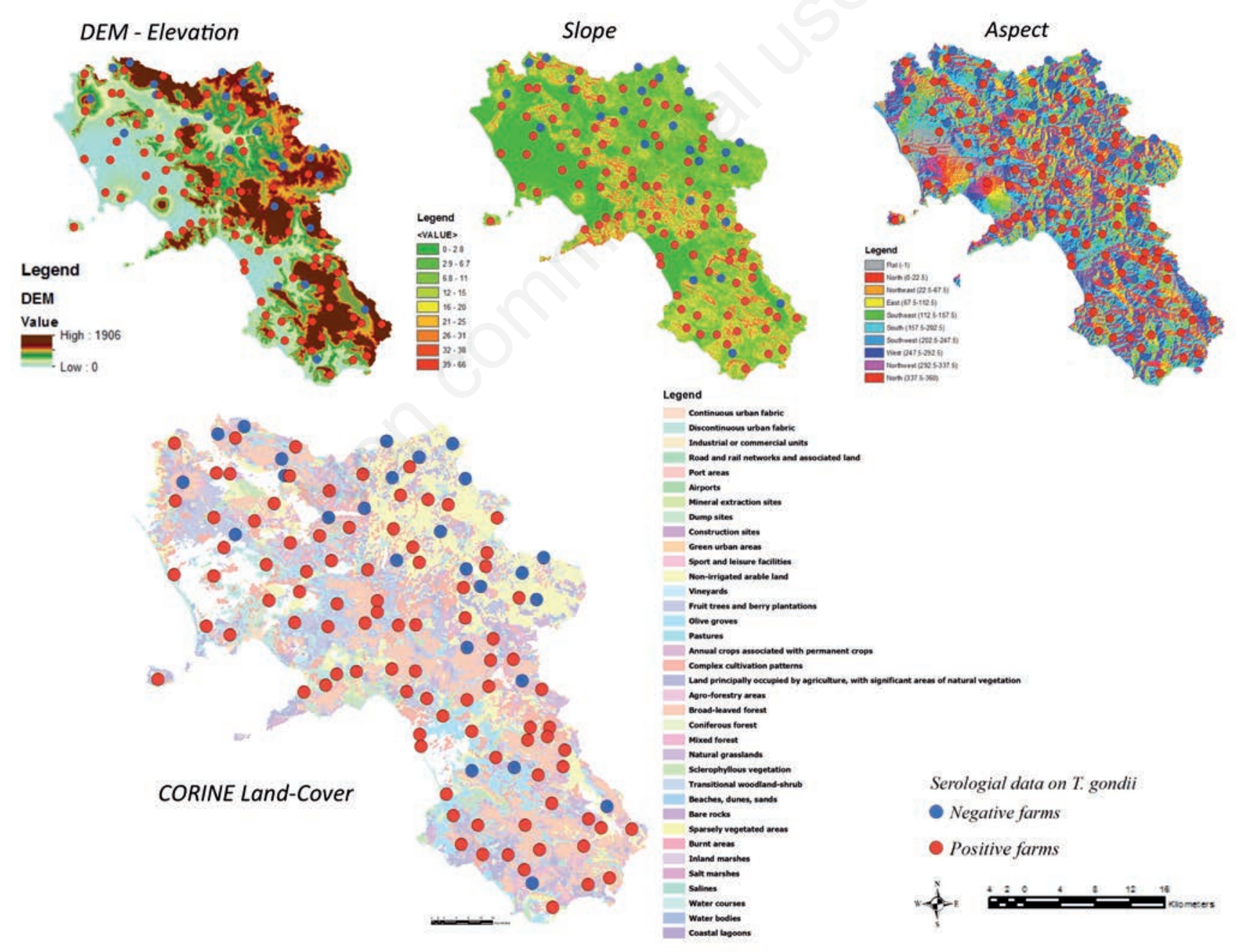

Figure 2. Overlapping of serological results and predominant Corine Land Cover classes, elevation, aspect, and slope steepness in the study area. 
CLC permitted the identification of 13 predominant level 3-classes in the study area. They belonged mainly to two level 1-classes, agricultural (64.5\%) and forest/semi-natural (31.2\%) areas. We did not find any association between seroprevalence and an aspect-independent variable; similar results were reported by Djokić et al. (2014) for goats in Serbia, while Kantzoura et al. (2013) found a significant higher prevalence of the parasite in ovine farms located in forest and urban/crop areas in Greece. Nevertheless, such results are difficult to compare to our study because we mapped territory at a more detailed level (third level of CLC land cover nomenclature), so we had a larger number of land classes in our study than they did. Several studies have analysed farm risk factors associated with $T$. gondii seropositivity in sheep (Klun et al., 2006; Vesco et al., 2007; Romanelli et al., 2007; Tzanidakis et al., 2012; Cenci-Coga et al., 2013; Alvarado-Esquivel et al., 2013; Kantzoura et al., 2013). However, comparisons between the results of these studies are not straightforward due to differences in epidemiological units (e.g. animal $v s$ farm), laboratory analysis (IFAT $v s$ ELISA) and different risk factors considered. An important finding was the fact that the occurrence of $T$. gondii was significantly higher in farms with mixed production than farms with only meat production. None of the abovecited studies included this variable in its statistical analysis as a potential risk factor for ovine toxoplasmosis. This finding could be related to the fact that, in a dairy farm, the farmers tend to keep the sheep that produce larger quantities of milk for years and, as a consequence, there is a presence of older animals in the flock. Many studies have shown that the probability of being infected is positively correlated to age of the sheep (Dubey, 2009), therefore a higher seroprevalence in farm with mixed production might be a consequence of such higher average age of animals in the flock.

In agreement with many other research groups (CosendeyKezenLeite et al., 2014; Cenci-Coga et al., 2013; García-Bocanegra et al., 2013; Tzanidakis et al., 2012), our analysis did not show any effect of the presence of cats in the farm or grazing area and serological prevalence in the sheep. This is, however, a contended issue reported by several authors (Mainar et al., 1996; Skjerve et al., 1998; Vesco et al., 2007; Romanelli et al., 2007; Andrade et al., 2013). Basically, it must be admitted that the presence of cats in a sheep farm, as well as in grazing pastures, could be a relevant risk factor for ovine, because of the risk of contamination of feed and water with oocysts. For instance, CenciCoga et al. (2013) reported a higher farm prevalence in farms where stray cats are allowed to access to animals' water, while the presence of resident or stray cats on farm was not significant. Similarly, Romanelli et al. (2007) found a positive relationship between the number of infected sheep and access of cats to farm food deposits.

Only very few studies have evaluated if the joint presence of sheep and other species of animals (excluding cat species) in the same farm or pasture can affect the within-flock prevalence of T. gondii (WaltnerToews et al., 1991; Tzanidakis et al., 2012). Using a multivariate model, the former researchers found a higher seroprevalence in ovine farms where pigs were also raised or farms where flocks share the pasture with other species. However, neither our study nor any other supports the idea that the contact with animal species other than the felines can be a risk factor for ovine toxoplasmosis.

Despite the fact that type or origin of the water supply has been frequently demonstrated to be a potential risk factor (Waltner-Toews et al., 1991; Vesco et al., 2007; Tzanidakis et al., 2012; Andrade et al., 2013), we did not find any statistical relationship with the seroprevalence of the parasite and presence of a water source in the main grazing area. Separately, we also tested different sources of water (spring, river, stream or lake) but did not find any effect on the within-flock occurrence of $T$. gondii (data not shown).
In contrast to some authors (Skjerve et al., 1998; Alvarado-Esquivel et al., 2013; Kantzoura et al., 2013), we did not find a clear association between altitude and occurrence of toxoplasmosis. In our results, however, similarly to study by Kantzoura et al. (2013), we found that the seropositive rate of flocks, which grazed in mountain pastures, was indeed lower than flocks, which had their main pasture area at lower elevation but not strongly so. Mountain pasture might be less contaminated with oocysts because of a lower anthropisation and, consequently a lower domestic cat population density; this could be the reason we found differences in seroprevalence in our study. This hypothesis is supported by the fact that prevalence rate of $T$. gondii is lower in transhumance flocks since this practice consist in moving the sheep to mountain pastures during the summer.

Unlike other similar studies, we followed a grid-based approach to select the farms involved in the study. This type of sampling is particularly effective for geospatial investigations because it permits researchers to obtain data from the whole study area and, consequently, allows a more representative picture of the territory. Another strong point is that our study involved a higher number of flocks compared to other similar studies (Kantzoura et al., 2013; Cenci-Goga et al., 2013; Andrade et al., 2013). However, in consideration of the type of regression model we used, the number of animals tested per flock might not have been sufficient to estimate the within-flock prevalence with an adequate level of accuracy.

\section{Conclusions}

Population-wise, our study mirrored the rearing conditions in Campania Region, so a vast proportion of flocks were seasonally or permanently on pasture (96.0\%). Since this type of farming system implies that animals have a high number of opportunities to be exposed to infectious T. gondii oocysts from many different sources of contamination (Guo et al., 2015), differences in levels of within-flock seroprevalence could be expected. However, with exception of the type of production and some environmental/management variables, few issues seemed to affect the risk of ovine toxoplasmosis.

Despite advances in our understanding of ovine toxoplasmosis, some aspects of the infection in sheep obviously require further research efforts. Therefore, a coordinated national-scale survey on toxoplasmosis in livestock - based on homogeneous sampling and laboratory techniques - is strongly needed, in order to better assess the actual epidemiological situation of this under-estimated zoonosis in livestock and to clarify factors that influence its presence and distribution.

\section{References}

Afonso E, Germain E, Poulle ML, Ruette S, Devillard S, Say L, Villena I, Aubert D, Gilot-Fromont E, 2013. Environmental determinants of spatial and temporal variations in the transmission of Toxoplasma gondii in its definitive hosts. Int J Parasitol 2:278-85.

Ahlers AA, Mitchell MA, Dubey JP, Schooley RL, Heske EJ, 2015. Risk factors for Toxoplasma gondii exposure in semiaquatic mammals in a freshwater ecosystem. J Wildlife Dis 51:488-92.

Alvarado-Esquivel C, Silva-Aguilar D, Villena I, Dubey JP, 2013. Seroprevalence and correlates of Toxoplasma gondii infection in domestic sheep in Michoacán State, Mexico. Prev Vet Med 112:4337 . 
Andrade MMC, Carneiro M, Medeiros AD, Neto VA, Vitor RWA, 2013. Seroprevalence and risk factors associated with ovine toxoplasmosis in Northeast Brazil. Parasite 20:20.

Casartelli-Alves L, Amendoeira MRR, Boechat VC, Ferreira LC, Carreira JCA, Nicolau JL, Trindade EPF, Peixoto JNB, Magalhães MAFM, Oliveira RVC, Schubach TMP, Menezes RC, 2015. Mapping of the environmental contamination of Toxoplasma gondii by georeferencing isolates from chickens in an endemic area in Southeast Rio de Janeiro State, Brazil. Geospat Health 10:311.

Cenci-Goga B, Ciampelli A, Sechi P, Veronesi F, Moretta I, Cambiotti V, Thompson PN, 2013. Seroprevalence and risk factors for Toxoplasma gondii in sheep in Grosseto district, Tuscany, Italy. BMC Vet Res 9:25.

Chadwick EA, Cable J, Chinchen A, Francis J, Guy E, Kean EF, Paul SC, Perkins SE, Sherrard-Smit E, Wilkinson C, Forman DW, 2013. Seroprevalence of Toxoplasma gondii in the Eurasian otter (Lutra lutra) in England and Wales. Parasite Vector 6:75.

Cosendey-KezenLeite RI, de Oliveira FC, Frazão-Teixeira E, Dubey JP, de Souza GN, Ferreira AM, Lilenbaum W, 2014. Occurrence and risk factors associated to Toxoplasma gondii infection in sheep from Rio de Janeiro, Brazil. Trop Anim Health Pro 46:1463-6.

Djokić V, Klun I, Musella V, Rinaldi L, Cringoli G, Sotiraki S, DjurkovićDjaković 0, 2014. Spatial epidemiology of Toxoplasma gondii infection in goats in Serbia. Geospat Health 8:479-88.

Dubey JP, 2009. Toxoplasmosis in sheep-the last 20 years. Vet Parasitol 163:1-14.

Fusco G, Rinaldi L, Guarino A, Proroga YT, Pesce A, De Marco G, Cringoli G, 2007. Toxoplasma gondii in sheep from the Campania region (Italy). Vet Parasitol 149:271-4.

García-Bocanegra I, Cabezón 0, E. Hernández, Martínez-Cruz MS, Martínez-Moreno Á, Martínez-Moreno J, 2013. Toxoplasma gondii in ruminant species (cattle, sheep, and goats) from Southern Spain. J Parasitol 99:438-40.

Guo M, Dubey JP, Hill D, Buchanan RL, Gamble HR, Jones JL, Pradhan AK, 2015. Prevalence and risk factors for Toxoplasma gondii infection in meat animals and meat products destined for human consumption. J Food Protect 8:457-76.

Innes EA, Bartley PM, Buxton D, Katzer F, 2009. Ovine toxoplasmosis. Parasitology 136:1887-94.

Italian Animal Register, 2016. https://www.vetinfo.sanita.it/

Johnson CK, Tinker MT, Estes JA, Conrad PA, Staedler M, Miller MA, Jessup DA, Mazet JA, 2009. Prey choice and habitat use drive sea otter pathogen exposure in a resource-limited coastal system. $P$ Natl Acad Sci 106:2242-7.

Kantzoura V, Diakou A, Kouam MK, Feidas H, Theodoropoulou H, Theodoropoulos G, 2013. Seroprevalence and risk factors associated with zoonotic parasitic infections in small ruminants in the Greek temperate environment. Parasitol Int 62:554-60.

Klun I, Djurkovic-Djakovic 0, Katic-Radivojevic S, Nikolic A, 2006. Cross-sectional survey on Toxoplasma gondii infection in cattle, sheep and pigs in Serbia: seroprevalence and risk factors. Vet
Parasitol 135:121-31.

Kulldorff M, 1997. A spatial scan statistics. Commun Stat A-Theor 26:1481-96.

Mainar RC, de la Cruz C, Asensio A, Domìnguez L, Vàzquez-Boland JA, 1996. Prevalence of agglutinating antibodies to Toxoplasma gondii in small ruminants of the Madrid region, Spain, and identification of factors influencing seropositivity by multivariate analysis. Vet Res Commun 20:153-9.

Miller MA, Grigg ME, Kreuder C, James ER, Melli AC, Crosbie PR, Jessup DA, Boothroyd JC, Brownstein D, Conrad PA, 2004. An unusual genotype of Toxoplasma gondii is common in California sea otters (Enhydra lutris nereis) and is a cause of mortality. Int $\mathrm{J}$ Parasitol 34:275-84.

Opsteegh M, Prickaerts S, Frankena K, Evers EG, 2011. A quantitative microbial risk assessment for meatborne Toxoplasma gondii infection in The Netherlands. Int J Food Microbiol 150:103-14.

Rinaldi L, Scala A, 2008. Toxoplasmosis in livestock in Italy: an epidemiological update. Parassitologia 50:59-61.

Rinaldi L, Biggeri A, Musella V, Waal T de, Hertzberg H, Mavrot F, Torgerson PR, Selemetas N, Coll T, Bosco A, Grisotto L, Cringoli G, Catelan D, 2015. Sheep and Fasciola hepatica in Europe: the GLOWORM experience. Geospat Health 9:309-17.

Romanelli PR, Freire RL, Vidotto 0, Marana ERM, Ogawa L, De Paula VSO, Garcia JL, Navarro IT, 2007. Prevalence of Neospora caninum and Toxoplasma gondii in sheep and dogs from Guarapuava farms, Parana State, Brazil. Braz Res Vet Sci 82:202-7.

Skjerve E, Waldeland H, Nesbakken T, Kapperud G, 1998. Risk factors for the presence of antibodies to Toxoplasma gondii in Norwegian slaughter lambs. Prev Vet Med 35:219-27.

Tenter AM, Heckeroth AR, Weiss LM, 2000. Toxoplasma gondii: from animals to humans. Int J Parasitol 30:1217-58.

Tzanidakis N, Maksimov P, Conraths F, Kiossis E, Brozos C, Sotiraki S, Schares G, 2012. Toxoplasma gondii in sheep and goats: seroprevalence and potential risk factors under dairy husbandry practices. Vet Parasitol 190:340-8.

VanWormer E, Conrad PA, Miller MA, Melli AC, Carpenter TE, Mazet JAK, 2013. Toxoplasma gondii, source to sea: higher contribution of domestic felids to terrestrial parasite loading despite lower infection prevalence. Eco Health 10:277-89.

VanWormer E, Miller MA, Conrad PA, Grigg ME, Rejmanek D, Carpenter TE, Mazet JA, 2014. Using molecular epidemiology to track Toxoplasma gondii from terrestrial carnivores to marine hosts: implications for public health and conservation. PLoS Negl Trop Dis 8:e2852.

Vesco G, Buffolano W, La Chiusa S, Mancuso G, Caracappa S, Chianca A, Villari S, Currò V, Liga F, Petersen E, 2007. Toxoplasma gondii infections in sheep in Sicily, southern Italy. Vet Parasitol 146:3-8.

Waltner-Toews D, Mondesire R, Menzies P, 1991. The seroprevalence of Toxoplasma gondii in Ontario sheep flocks. Can Vet J 32:734-7. 